\title{
Programa Minas Rural e ATER: análise da extensão rural midiatizada
}

\section{TV Program Minas Rural: analysis of the rural extension mediated}

\author{
Daniela Leal \\ dulyleal@gmail.com \\ Graduada em Comunicação Social, MBA em Marketing Estratégico (UFT). Mestranda \\ em Extensão Rural (UFV)
}

\section{Ivonete da Silva Lopes}

ivonetelopes@ufv.br

Doutora em Comunicação pela Universidade Federal Fluminense (UFF). Professora do Departamento de Economia Federal de Viçosa (UFV)

Recebido em: 29/09/2017

Aprovado em: 20/10/2017
Revista do Programa de Pós-Graduação em Extensão Rural (UFV) 


\title{
RESUMO
}

Este artigo procura entender como o programa Minas Rural, produzido pela Empresa de Assistência Técnica e Extensão Rural do Estado de Minas Gerais (Emater), representa a prática extensionista e, também, os valores que podem estar imbricados na difusão dos resultados da extensão rural. Foram analisados os conteúdos do programa Minas Rural veiculados nos meses de agosto e setembro de 2016 e os enquadramentos adotados nas reportagens sobre os resultados dos serviços de ATER prestados pela Emater-MG. Como resultado, percebe-se que o Minas Rural ratifica a imagem de um meio rural pouco homogêneo, estruturado em bases econômicas e do agronegócio.

Palavras-chave: Extensão Rural; Comunicação Rural; Minas Rural.

\begin{abstract}
This paper sought to understand how the TV program Minas Rural, produced by the Empresa de Assistência Técnica e Extensão Rural do Estado de Minas Gerais (Emater), represents the extensionist practice and also the values that may be imbricated in the diffusion of rural extension results. The contents of the program Minas Rural published in August and September 2016 and, also, the frameworks adopted in the reports about the results of the ATER services provided by Emater-MG were analyzed. As a result, it can be seen that Minas Rural ratifies the image of a homogeneous rural environment, structured on economic and agribusiness bases.
\end{abstract}

Keywords: Rural extension, rural communication, Minas Rural. 


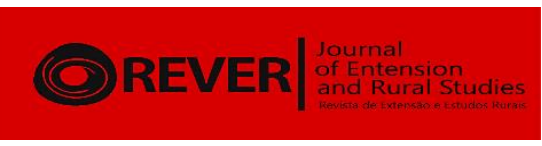

Introdução

O papel atribuído ao extensionista rural é de agente de mudanças, um dos elos entre o rural e o urbano, que, atua como interlocutor das políticas públicas no meio rural e compartilha os avanços da ciência e as novas tecnologias adequadas ao desenvolvimento sustentável do setor. Enquanto agente de mudanças, o extensionista se encontra num campo conflituoso, no qual muitos atores públicos e privados exercem influência, promovendo interesses que podem favorecer ou não o meio rural, nas diversas dimensões, como as econômicas e sociais.

Ao longo da história da extensão rural no Brasil, a relação desta atividade com os sujeitos rurais ocupou diferentes espaços, desde os campos da revolução verde, com seus incentivos produtivistas de cunho mercadológico, aos lugares de participação social e princípios agroecológicos. Da mesma maneira, as formas de comunicar com os sujeitos já transitaram desde as abordagens behavioristas às dialógicas. A prática extensionista também passou ser mediada por dispositivos tecnológicos, como o rádio e a televisão. Especificamente a mídia televisiva tem sido uma aliada na prática da extensão rural e na promoção de novas tecnologias para o homem do campo.

Baseado neste contexto da atividade extensionista midiatizada, este artigo analisa as ações de prestação de serviço de Assistência Técnica e Extensão Rural (ATER) veiculadas pelo programa Minas Rural. Produzido pela Empresa de Assistência Técnica e Extensão Rural do Estado de Minas Gerais (Emater-MG), atende 400 mil agricultores no estado com objetivo de promover o desenvolvimento rural sustentável. É veiculado há 17 anos, com produção semanal, transmitido pelas emissoras Rede Minas, Terra Viva, TV Horizonte e Canal AgroBrasil e está disponível na internet no site da Emater.

O Minas Rural atua como prestador de serviço ATER e divulgador dos resultados dos serviços de extensão rural, portanto, entender como o programa da Emater representa a prática extensionista e, também os valores que podem estar imbricados na difusão dos resultados da extensão constituem o objetivo deste trabalho. Visando compreender as principais temáticas que permeiam a prática extensionista na mídia televisiva, voltada para o meio rural, esta pesquisa analisou os conteúdos do programa Minas Rural veiculados nos meses de agosto e setembro de 2016 e os enquadramentos adotados nas reportagens sobre os resultados dos serviços de ATER prestados pela Emater-MG, por meio de uma abordagem qualitativa. 


\section{Breve panorama da extensão rural no Brasil}

Na primeira metade do século XX, governos latino-americanos, no intuito de informar e persuadir os agricultores a adotarem boas práticas em suas atividades, iniciaram convênios com agências norte-americanas como a Associação Internacional Americana (AIA), que lançando mão de meio audiovisual para difundir o conteúdo técnico-cientifico, colaboravam para uma adequação da agricultura ao novo mercado pósguerra. A entidade foi criada pelos irmãos Rockfeller $^{1}$, que além de ratificar o expansionismo americano atendia aos anseios das elites locais. Desta forma, no Brasil a comunidade rural passa a ser atendida tecnicamente de forma coletiva e extraescolar, não sendo levado em consideração seu caráter heterogêneo. Para difundir um modelo agropecuário neste período, de acordo com Rosa (2008, p.19) “O suporte teórico veio dos Estados Unidos, aliando-se a cartazes, folhetos, cartilhas, audiovisuais, programas de rádio e de vídeos foram introduzidos nos contextos histórico, cultural e político daquela época no Brasil".

Em 1948, Rockfeller assina um convênio entre a AIA e o governo do estado de Minas Gerais, criando assim a Associação de Crédito e Assistência Rural (ACAR), atual Empresa de Assistência Técnica e Extensão Rural (Emater), com objetivo de oferecer assistência técnica e crédito rural supervisionado, impulsionando pela primeira vez no Brasil a Extensão Rural enquanto política pública. Concebendo o homem rural como “desnutrido, ignorante, isolado e anônimo" (FONSECA, 1985, p.93), a prática extensionista apresentava como solução a modernização do seu modo de vida, sem questionar arranjos socioeconômicos que pudessem determinar estas condições. Desta forma, a ACAR, com seu caráter humanista assistencialista, se expande e aumenta o número de escritórios, replicando o modelo de equipes formadas por um supervisor agrícola, uma supervisora doméstica, um auxiliar administrativo e um Jipe Willes (FONSECA, 1985).

No começo da década de 1960 no Brasil, através de uma aliança entre elites nacionais e capital estrangeiro, motivada também por alinhamento político, o governo,

\footnotetext{
${ }^{1}$ Nelson Rockefeller (1908-1979), neto de John D. Rockefeller, fundador da petroleira Standard Oil executivo do conglomerado familiar no começo de carreira, mais tarde subsecretário de Estado para Assuntos Latino-Americanos dos Estados Unidos, quatro vezes governador de Nova York, vice-presidente americano na gestão de Gerald Ford (1974-1977), veio dez vezes ao Brasil, algumas em missão oficial, outras por iniciativa própria. Por meio de duas associações criadas por ele, a AIA e a Ibec, Rockefeller começou a investir por aqui para manter o país na órbita dos Estados Unidos, com receio do comunismo. (TOTA, Antonio P. Meu amigo americano. Companhia das Letras São Paulo 2014)
} 
agora militar, passou a privilegiar médios e grandes agricultores do Sul e Sudeste, que davam ênfase na produção para o comércio exterior (GRISA e SCHNEIDER, 2014), desconsiderando a agricultura de autoconsumo e das pequenas propriedades.

Desta forma, as ACARs passam a contar com especialistas por produtos para difundir os pacotes tecnológicos, explicitando agora a característica produtivista do serviço de ATER, que passam a fomentar a produção em grande escala de commodites e a implementação efetiva do modelo do agronegócio para o campo brasileiro, promovendo assim toda uma nova cadeia industrial, baseada no uso máquinas e equipamentos, sementes híbridas ou melhoradas, agrotóxicos e fertilizantes químicos sintéticos.

A prática extensionista baseada no difusionismo produtivista, segundo o paradigma de Everett Rogers (1974), tinha por objetivo incorporar inovações junto aos agricultores chamados progressistas, gerando uma reação em cadeia, encurtando, desta forma, o tempo intermediário entre uma inovação pelos centros de pesquisa e sua adoção generalizada pelos agricultores (BORDENAVE, 1983). Com atuação focada na transferência de tecnologias, fortaleceu a ideia de uma extensão voltada a técnicas de venda e ao marketing, introduzindo entre os agricultores novas propostas, de maior eficiência produtiva. Como consequência, a autonomia produtiva no campo foi comprometida, colaborando com o agravamento da concentração de terras, da poluição, do êxodo rural, empobrecimento do meio rural e com a exclusão social dos agricultores de autoconsumo ou que acessavam apenas os mercados locais de comercialização.

O processo de redemocratização do Brasil possibilitou o começo das mudanças no trato da agricultura familiar, cabendo aos pesquisadores, técnicos e extensionistas a tarefa de articular novas formas e caminhos para atender a diversidade e particularidades do rural brasileiro, trazendo o diálogo e o uso de metodologias educacionais ativas para o processo de se fazer extensão no Brasil (OLIVEIRA, 2015).

Neste contexto, se fortalece a proposta para se pensar a extensão rural em uma perspectiva mais dialógica (FREIRE, 1977), no qual o agricultor não está desassociado de sua realidade concreta e histórica, levando em conta os sentidos e significados que estes dão a sua realidade.

Ainda segundo Freire (1977), existem opções de prática de extensão mais "libertadoras", nas quais o extensionista pode exercer seu papel de educador, visto que não há nenhuma categoria de persuasão que tenha cunho justificável. Neste campo 
educacional, o objeto da extensão se torna sujeito pela sua postura "curiosa face ao mundo" (Ibidem), diferentemente de uma visão autoritária, onde objeto e sujeito se polarizam enquanto invadido e invasor cultural.

A abordagem humanista crítica da extensão rural vai contra a domesticação do sujeito rural, numa busca pela transformação constante da realidade, na qual tanto o técnico quanto o agricultor podem ser agentes de mudança. Esta visão de mundo demanda uma temporalidade maior para que os efeitos venham à tona, o que se choca com os prazos e a lógica produtivista, muitas vezes desmotivando ações institucionais com esta ótica.

No início da década de 1990, o governo Fernando Collor, orientado por políticas neoliberais, e pensando exclusivamente na agricultura de exportação, que já não tinha dependência de serviços de extensão rural pública, extingue a Empresa Brasileira de Extensão Rural (Embrater), ocasionando a desorganização, enfraquecimento e desmonte do extensionismo público no país (CAPORAL, 1998). Como resultado deste modelo difusionista e de seu caráter seletivo, a desigualdade social no meio rural se acentuou, ratificando uma estrutura agrária desfavorável àqueles que não estavam aptos para se inserirem nos sistemas socioeconômicos.

Como, até meados dos anos 1990, não havia nenhum tipo de política pública nacional voltada para os agricultores familiares, estes se viam obrigados a seguir os mesmos trâmites dos grandes produtores para conseguir crédito. Situação que gerou reivindicações populares exigindo maior apoio no processo de abertura comercial. Entretanto, a Organização das Nações Unidas para Agricultura e Alimentação (FAO) e o Instituto Nacional de Colonização e Reforma Agrária (Incra) definiram no ano de 1994 as especificações da Agricultura Familiar (AF), indicando que a expansão e o fortalecimento da AF seriam estratégias viáveis para o desenvolvimento rural brasileiro.

Através de árduas mobilizações e articulações de movimentos sociais, atores relevantes na elaboração dos planos e projetos para a agricultura familiar no Brasil, possibilitou-se o início do processo de organização de políticas públicas voltadas para atender os anseios e necessidades dos pequenos agricultores (GRISA e SCHNEIDER, 2014). Como resultado, em 1996 foi lançado o Programa Nacional de Fortalecimento da Agricultura Familiar (Pronaf), com missão de ser um instrumento capaz de aumentar as possibilidades de investimento dos AF.

$\mathrm{Na}$ mesma década, o termo agronegócio se popularizou por sua capacidade de explicar a nova perspectiva rural, caracterizada pelo crescimento das exportações de 
produtos agrícolas e agroindustriais, traduzindo a complexa integração do setor, reforçada pelo uso de maquinários, inovações tecnológicas, insumos modernos e assistência de cientistas, pesquisadores e especialistas. Esta integração estabeleceu novas relações de trocas entre estes setores da economia, apresentando agora um meio rural dependente da indústria, desde a compra de sementes (muitas vezes híbridas, fortalecendo a dependência), compra de insumos e máquinas, até o momento dos beneficiamentos e transporte. Desta forma, muitos agricultores se tornaram também dependentes do sistema financeiro, pois para conseguir acessar a modernização recorreram a financiamentos e, endividados, precisam produzir em maior quantidade para quitar seus dividendos.

No início do século XXI, a eleição de um governo popular faz ressurgir a extensão rural no Brasil, voltada, agora, à construção de um modelo de desenvolvimento ambientalmente sustentável e socialmente includente. Neste cenário houve a transferência legal dos serviços de ATER do Ministério da Agricultura, Pecuária e Abastecimento (MAPA) para o Ministério do Desenvolvimento Agrário (MDA). Surgiram, então, políticas de reforma e reordenamento agrário, inclusão produtiva, fortalecimento de ampliação do crédito rural e criação e ampliação dos mercados institucionais.

Muito embora as exportações agrícolas provenientes de grandes plantações respondem por saldos positivos na balança comercial brasileira, o abastecimento alimentar no país é em 70\% originário da agricultura familiar (PORTAL BRASIL, 2015), que se destaca por desenvolver culturas variadas, mesmo que em menor escala.

Estas conquistas se institucionalizam em 2004 com a criação da Política Nacional de Assistência Técnica e Extensão Rural (PNATER), que passa a considerar a diversidade e as desigualdades da agricultura familiar, a promoção do desenvolvimento rural sustentável baseado nos princípios da agroecologia, uma gestão simplificada e a adoção de metodologias participativas. Nesta concepção participativa, os agricultores são inseridos no processo "desde os atos da problematização até os atos de decisão" (COELHO, 2005, p 87), já que a unilateralidade no processo comunicacional sustenta o paradigma hegemônico.

O Estado reconhece, então, a pluralidade institucional de ATER, tornando-se fomentador da oferta destes serviços. Nesse momento, a prática extensionista assume, também, o papel de mediação entre o sujeito rural e as diferentes políticas públicas, inclusive de infraestrutura como credito fundiário, "Minha Casa Minha Vida" e "Luz para Todos". 
Apesar do endosso popular que vinha direcionando as políticas públicas de ATER, a PNATER de 2010, através da Lei 12.188-2010, apresenta um "retrocesso no campo da extensão rural contemporânea" (CAPORAL, 2011), com, por exemplo, a eliminação do princípio da agroecologia do texto principal. Sobre o modelo operacional de repasses de recursos, as contratações de serviços de ATER passam a ser voltadas para chamadas públicas padronizadas, ao invés de convênios, o que estabelece modelos metodológicos "inibidores" do processo participativo e serviços de curto prazo. A descontinuidade dos serviços de ATER sempre se caracterizou como um fator limitante de resultados.

Como fruto de tensões políticas internas e até mesmo do interesse da Confederação Nacional da Agricultura (CNA) pela extensão rural, no final de 2013 o Governo Federal cria a Agência Nacional de Assistência Técnica e Extensão Rural (Anater), orientando novamente o serviço de ATER para o caminho do difusionismo tecnológico voltado ao mercado e à agricultura moderna. A Agência nasce com a competência de integrar o sistema de extensão rural ao da pesquisa agropecuária, mais uma vez interpretando o meio rural brasileiro apenas como espaço de produção agrícola.

Em síntese, a busca por resultados econômicos e produtividade e o anseio por conquistas sociais tem dividido o campo da Extensão Rural, refletindo diferentes visões de mundo. Para Caporal (2006), o papel do extensionista sofre de indefinição, visto que este acaba se envolvendo em muitas e variadas demandas e estabelecendo relações provisórias com os sujeitos rurais, em busca de "resultados a qualquer custo".

Em 2016, o Governo Temer extingue o Ministério do Desenvolvimento Agrário, transferindo suas competências para a Secretaria Especial de Agricultura Familiar e do Desenvolvimento Agrário, na Casa Civil. Embora a medida seja recente, pode-se perceber que os próximos passos da prática extensionista se direcionam para o trabalho em um espaço agrário socialmente mais desigual e com menos suporte governamental.

\section{A comunicação voltada ao meio rural}

A comunicação rural compreende múltiplas fluxos de informação, de diálogo e de influência recíproca existente entre pluralidade dos sujeitos rurais, e entre estes e os demais setores afetados pela dinâmica do campo.

A necessidade de se pensar uma comunicação voltada para o sujeito rural vem das particularidades deste universo, muitas vezes contrastante com o espaço urbano. Fatores 
como o baixo nível de instrução; o isolamento geográfico; a precariedade dos transportes; o excesso de horas trabalhadas no sol quente que geram cansaço e o fazem querer descansar em detrimento a vida social; o conflito entre patrões e trabalhadores trazem características especiais a este processo de comunicação.

Bordenave (1983) faz críticas ao modelo de comunicação difusionista por apresentar um problema pedagógico, de ensino-apredizagem, pois não é suficiente usar palavras e imagens para comunicar uma tecnologia, é preciso ensinar, para que os agricultores, os receptores deste processo, possam dominá-la. Enfatiza o autor que a comunicação rural deveria sustentar uma conscientização popular de participação ativa nos processos de mudança social e de construção de uma sociedade mais democrática.

A comunicação capaz de gerar nos indivíduos uma mudança comportamental precisa ser dialógica, uma comunicação na qual todos devem ter direito à fala em uma relação de mútuo respeito e se eduquem mutuamente. Para Paulo Freire (1977, p.43), ser dialógico é antes "empenhar-se na transformação constante da realidade", considerando que "este diálogo não pode travar-se numa relação antagônica". A unilateralidade no processo comunicacional sustenta o paradigma hegemônico e ignora o cotidiano do sujeito rural, espaço onde este conhecimento pode encontrar sentido, efeitos e reações, ou não, a depender de um complexo véu cultural.

As formas como as informações são disseminadas e o conhecimento é construído no meio rural vêm se transformando com o uso da televisão. O número de aparelhos de TV no meio rural tem aumentado, principalmente com o uso de antena parabólica, que já alcança 78,5\% das TVs (PORTAL BRASIL, 2014). A mídia televisiva, com sua difusão de textos e imagens carregadas de sentidos, em constante movimento de interação, estabelece múltiplas relações com a audiência, "anima, reflete e exprime" a experiência humana (SILVERSTONE, 1999 p.147), sendo tanto um bem de consumo quanto um instrumento para o consumo.

O campo da recepção, ou dos consumidores dos meios de comunicação, não pode ser visto como homogêneo É, antes, "espaço de negociação, apropriação e produção" (CANTÚ e CIMADEVILLA, 2015), onde cotidiano e as diversas modalidades de recepção influenciam para uma construção do sentido e apropriação da mensagem. A recepção está desassociada da mera exposição e se configura um processo "construtivo, dialético e conflitivo" (Ibidem). O consumo dos meios, como fonte de informação sobre a realidade, cumpre uma função geral de construir um marco de referências sobre o 
presete social, geralmente, outorgando ao receptor um papel mais ordenador de sua própria realidade.

Através do seu caráter massivo, a televisão ratifica o modelo difusionista de comunicação rural, que objetiva minimizar o tempo entre o lançamento de uma inovação pelos centros de pesquisa e sua adoção generalizada pelos agricultores, ocupando assim um espaço de hegemonia. $\mathrm{O}$ discurso midiático que alcança o sujeito rural, na maioria das vezes, propõe óticas argumentativas sobre a realidade comprometidas com suas lógicas de produção urbana e ignora vários elementos do cotidiano rural que contribuem para a produção de sentido (BORDENAVE, 1983), possibilitando ao agricultor um papel pouco participativo na dinâmica comunicativa.

A mídia se preocupa em retratar um universo rural que seja identificado com os modelos do agronegócio, promovendo "deslocamentos semânticos sobre o significado e a composição social do meio rural, capazes de sustentar e expressar um imaginário em conformidade com a lógica da expansão do capital" (OLIVEIRA, 2012, p.125). A pluralidade dos sujeitos rurais é geralmente ignorada, tendo espaço de visibilidade apenas aqueles que se encaixam nas categorias de empresários rurais ou produtores, de pequeno, médio ou grande porte, reforçando a relação entre a atividade agrícola e comércio (e ou indústria).

Apesar desta característica de resistência, a comunicação se configura muitas vezes um jogo de forças, no qual interesses hegemônicos pautam as mensagens transmitidas. A televisão tem sido desde sua invenção veículo de forças ideológicas, e segundo Martín-Barbero (2006, p.299): “A maior influência da televisão não se produz através do tempo material que lhe dedicamos, mas através do imaginário que ela gera e pelo qual estamos sendo penetrados". Ao transformar o discurso técnico ou científico numa forma de linguagem mais acessível para o sujeito rural (GUIMARÃES, 2001), o comunicador gera um "produto", isento de neutralidade, que está inserido numa complexa rede produtiva e na maioria das vezes ligada à lógica do capital.

\section{Metodologia}

Os conteúdos veiculados pela mídia trazem intrinsecamente intenções que pode ser percebidas através de análises características no modo como o conteúdo é apresentado, ou seja, no enquadramento (framing) dado ao mesmo, especialmente no tocante a 


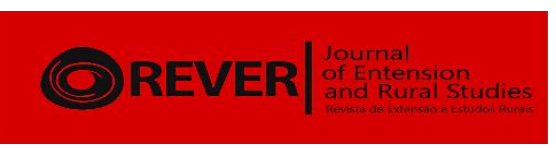

"seletividade e saliência" de certos aspectos, que podem se sobressair a outros. (ENTMAN, 1993). Para o autor, o "frame" tem a capacidade de definir problemas, diagnosticar causas, fazer julgamentos morais e sugerir soluções. Desta forma, espera-se que o público atribua maior valor a questões mais reclamadas pela mídia, e à medida que esta exposição aumenta, encontra mais identificação com a mesma.

Como recorte, o presente trabalho se concentrou em analisar o conteúdo das reportagens do programa, veiculadas no período compreendido entre agosto e setembro de 2016, totalizando oito programas. Como o Minas Rural está no ar há muito tempo, esta amostragem delimita uma abordagem atual do programa, considerando-se que ao longo de sua existência ele pode ter sido pautado por outras temáticas, que podem estar relacionadas à própria gestão da Emater ou a demandas passadas.

Esta pesquisa analisou o conteúdo de 19 reportagens do programa Minas Rural, além dos os enquadramentos dados aos resultados do trabalho da Emater, destacando aspectos qualitativos das reportagens, como elementos da narrativa que se encontram presentes ou não, e aspectos quantitativos, que têm como unidade de informação de base a frequência do aparecimento de certas características de conteúdo.

\section{Minas Rural}

Para prestar assistência técnica para os produtores rurais, a Emater-MG faz uso de tecnologias de comunicação, como televisão, através do programa Minas Rural, além de internet e rádio. Segundo dados da empresa, que está presente em cerca de 790 municípios do estado, o agricultor que recebe assistência técnica continuada consegue ter até quatro vezes mais produtividade em suas terras.

O programa televisivo produzido pela Emater-MG apresenta uma estrutura fixa, que se repete semanalmente, constituída de duas reportagens, em geral sobre resultados de trabalhos técnicos da empresa junto a produtores rurais, agenda de eventos e notícias do ramo agropecuário, a cotação do mercado agropecuário, uma dica técnica e uma receita dita "mineira". 


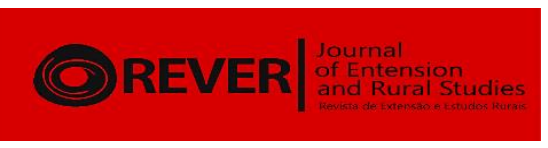

Quadro 1: Título das reportagens veiculadas entre 06/08/16 a 24/09/16

\begin{tabular}{|c|c|c|}
\hline Data & Título & Palavras-chave \\
\hline 06.08 .2016 & $\begin{array}{l}\text { Sorgo, capim bufel e milheto são culturas } \\
\text { incentivadas no norte de Minas }\end{array}$ & $\begin{array}{l}\text { Seca, agricultura familiar, culturas de } \\
\text { resistência }\end{array}$ \\
\hline 06.08 .2016 & $\begin{array}{l}\text { Em Brasília de Minas uma família buscou uma } \\
\text { alternativa bem diferente para melhorar a renda }\end{array}$ & Seca, renda, confecção \\
\hline 13.08.2016 & $\begin{array}{l}\text { Epamig celebra } 42 \text { anos e apresenta benefícios } \\
\text { da pesquisa agropecuária para a produção de } \\
\text { alimentos }\end{array}$ & Inovação, pesquisas, tecnologia \\
\hline 13.08.2016 & $\begin{array}{l}\text { Agriminas traz centenas de produtos da } \\
\text { agricultura familiar para a capital mineira }\end{array}$ & $\begin{array}{l}\text { Evento, agroindústria, agricultura } \\
\text { familiar }\end{array}$ \\
\hline 20.08.2016 & $\begin{array}{l}\text { Ex-marceneiro ganha a vida vendendo água de } \\
\text { coco, mel e doces cristalizados }\end{array}$ & $\begin{array}{l}\text { Sucesso, agroindústria, agricultura } \\
\text { familiar }\end{array}$ \\
\hline 20.08 .2016 & $\begin{array}{l}\text { Nas mãos das artesãs dos Rio Piracicaba a taboa } \\
\text { se transforma em peças utilitárias }\end{array}$ & Associação, tradição, artesanato \\
\hline 20.08.2016 & $\begin{array}{l}\text { Programa de Apoio para regularização de queijos } \\
\text { de pequeno porte }\end{array}$ & $\begin{array}{l}\text { Agroindústria, pequenos produtores, } \\
\text { normatização }\end{array}$ \\
\hline 27.08 .2016 & $\begin{array}{l}\text { Festas de Agosto movimentam Montes Claros, } \\
\text { no norte de Minas }\end{array}$ & Agricultura familiar, folclore, tradição \\
\hline 27.08 .2016 & $\begin{array}{l}\text { Famílias mineiras inscritas no Garantia Safra } \\
\text { começaram a receber o pagamento referente à } \\
\text { safra 2015-2016 }\end{array}$ & Seca, agricultura familiar, perda de safra \\
\hline 03.09 .2016 & $\begin{array}{l}\text { Como jovens produtores rurais estão se } \\
\text { destacando na atividade leiteira, com ajuda da } \\
\text { Emater. }\end{array}$ & $\begin{array}{l}\text { Jovens, geração de renda, agricultura } \\
\text { familiar }\end{array}$ \\
\hline 03.09 .2016 & $\begin{array}{l}\text { E as delícias proporcionadas pelo IV Festival de } \\
\text { Pão de Queijo e Artesanato, de São João Del Rei }\end{array}$ & $\begin{array}{l}\text { Tradição, promoção, } \\
\text { familiar }\end{array}$ \\
\hline 03.09 .2016 & $\begin{array}{l}\text { Recuperação de nascentes no município de } \\
\text { Dionísio }\end{array}$ & $\begin{array}{l}\text { Sustentabilidade, educação ambiental, } \\
\text { agricultura familiar }\end{array}$ \\
\hline 10.09.2016 & $\begin{array}{l}\text { Emater e Ibio desenvolvem atlas do Ribeirão do } \\
\text { Boi. }\end{array}$ & Paisagem, preservação, solução \\
\hline 10.09.2016 & $\begin{array}{l}\text { Conheça os segredos da cachaça artesanal } \\
\text { mineira }\end{array}$ & $\begin{array}{l}\text { Destilados, produção artesanal, micro e } \\
\text { pequenos empreendedores }\end{array}$ \\
\hline 10.09.2016 & Doce de leite Dom Coimbra & Qualidade, concurso, laticínios \\
\hline 17.09.2016 & $\begin{array}{l}\text { Final de semana regado a café e biscoito, em São } \\
\text { Tiago. }\end{array}$ & Evento, tradição, economia \\
\hline 17.09.2016 & Semana do Peixe estimula o consumo de pescado & $\begin{array}{l}\text { Consumo, renda fixa, agricultura } \\
\text { familiar }\end{array}$ \\
\hline 24.09.2016 & $\begin{array}{l}\text { Turismo alia atrativos religiosos, naturais e } \\
\text { gastronomia em Minas Gerais. }\end{array}$ & $\begin{array}{l}\text { Turismo religioso, artesanato, cultura } \\
\text { mineira }\end{array}$ \\
\hline 24.09.2016 & $\begin{array}{l}\text { Semana Internacional do Café atrai cafeicultores, } \\
\text { empresários e apreciadores da bebida para BH }\end{array}$ & Inovação, agricultura familiar, mulheres \\
\hline
\end{tabular}

Fonte: Elaboração própria.

A expressão "agricultura familiar" se repete de forma intensa nas diversas edições do programa, denotando que o programa dialoga com seu público. Também a tradição, 
que cria identificação com a audiência, é apresentada diversas vezes e de muitas formas, como festas, artesanatos e até santuários religiosos como na reportagem "Turismo alia atrativos religiosos, naturais e gastronomia em Minas Gerais". A matéria "Nas mãos das artesãs do Rio Piracicaba a taboa se transforma em peças utilitárias" contém expressões como "um novo olhar para a matéria prima", "resgate de tradição", "sucesso de mercado", "herdeiros da arte", "inclusão social", demonstrando a amplitude e a diversidade da tradição, assim como o da cultura. Nesta reportagem vale destacar o comentário de uma artesã da associação entrevistada que exprime sua satisfação após ter feito o curso do Serviço Nacional de Aprendizagem Rural (Senar) de fibras flexíveis: "Saímos do sol, graças a Deus, que não quero mais isso para mim".

Nas reportagens analisadas, ao todo dezenove, observou-se que quase metade delas (sete) se refere a eventos do ramo agropecuário no estado de Minas Gerais, como a celebração de 42 anos da Epamig, a Agriminas em Belo Horizonte, Festas de Agosto no município de Montes Claros, Festa do Café e Biscoito no município de São Tiago, a Semana do Peixe no município de Capitólio, entre outros. Ao reportar os eventos, a equipe jornalística do Minas Rural, na maior parte se reserva a explicar a importância do evento para a localidade e os impactos financeiros e sociais que refletem neste espaço. Geralmente algum gestor ou produtor local é entrevistado sobre os benefícios do evento, em geral econômicos, e também alguém do público é ouvido no papel de consumidor do evento. Expressões como "ganhando novos mercado", "maiores feiras do Brasil", "o melhor da agroindústria familiar", "bons negócios", "novos contatos“ são usadas para definir os aspectos vantajosos dos eventos. A reportagem "Epamig celebra 42 anos" traz o depoimento de um técnico que diz: "Quem adota tecnologia intensivamente tem renda e qualidade de vida", afirmação de aspecto óbvio, mas que ignora além de alternativas agrícolas que já foram incentivadas pelo Governo Federal, limitações socioeconômicas que excluem grande parte da população agrícola do uso intensivo da tecnologia.

Por outro lado, na matéria "Festas de Agosto movimentam Montes Claros, no Norte e Minas", além do folclore e tradição, a reportagem aborda o conceito da agroecologia, apresenta uma comunidade indígena e a troca de sementes crioulas, representando uma parte significativa do meio rural e que muitas vezes é ignorada pela mídia. Além destes pontos, a matéria cita a reforma agrária e a visibilidade do trabalho da mulher no campo, questões relevantes para o meio rural, embora pouco presentes na amostra estudada. 
A expressão "políticas públicas" aparece em diversas reportagens, trazendo para o discurso elementos de grande importância e familiaridade para o contexto da agricultura familiar. Na reportagem "Ex-marceneiro ganha a vida vendendo água de coco, mel e doces cristalizados" a repórter afirma que "com o acesso a políticas públicas, a prosperidade chegou e ficou". Levando em conta que nem todos os sujeitos rurais tiveram seus problemas resolvidos apenas porque tiveram acesso a políticas públicas, a repórter alia a característica da persistência ao sucesso do agricultor, fator que imprime na reportagem o discurso hegemônico da meritocracia. Da mesma forma, a matéria "Em Brasília de Minas, uma família buscou uma alternativa bem diferente para melhorar a renda"; a repórter apresenta a importância do "Programa Brasil Sem Miséria" para a família entrevistada. Embora o acesso ao programa tenha servido para melhorar a renda da família, o fator limitante de inclusão no mercado foi o fato desta residir próxima à cidade, pela maior facilidade de distribuição do produto.

A prática da extensão rural enquanto mediadora de políticas públicas é apresentada em muitas reportagens, ratificando o caráter pluralista da profissão, que vai da assistência técnica ao apoio com formulários. Neste contexto, o "Pronaf" é citado como fator de relevância para transformações no meio rural, como nas matérias "Programa de Apoio para regularização de queijos de pequeno porte". Segundo esta reportagem, graças ao Pronaf, o produtor adquiriu pasteurizadora e câmara fria em material inox, passou sua ordenha para o modo mecânico, e seguiu as demais orientações do Instituto Mineiro de Agropecuária (IMA) e da Agencia de Vigilância Sanitária (Anvisa) para comercializar seu produto em todo estado de Minas Gerais.

A orientação para uma responsabilidade ambiental é encontrada no programa em reportagens de cunho menos comercial, como "Recuperação de nascentes no município de Dionísio", embora o capital não deixe de dar o seu tom, por exemplo, quando se cita que "a água valoriza a propriedade". A matéria traz a ideia da preservação ambiental ao incentivar o cercamento de nascentes, evitando o pisoteio do gado. Também em "Emater e Ibio desenvolvem atlas do Ribeirão do Boi" o problema de ocupação do espaço da bacia hidrográfica, dividida em Área de Preservação Permanente (APP) e área para atividades produtivas, direciona o discurso para a preservação ambiental.

A ciência, quando divulgada no Minas Rural, é apresentada dentro de um problema, geralmente uma demanda técnica da Emater, e, na maior parte dos casos, a figura de um técnico da empresa é quem explica a solução do problema, muitas vezes 
utilizando linguagem mais técnica, embora as jornalistas se esforcem por realizar pequenas explicações de apoio.

As reportagens analisadas com foco nos resultados da empresa apresentam, na maior parte, muitos elementos que associam o sucesso de uso da técnica apreendida ao lucro comercial e geração de renda. Ao longo de algumas reportagens fica evidenciada a intenção de se promover o agronegócio como um modelo de sucesso a ser copiado pelos demais, como na matéria "Como jovens produtores rurais estão se destacando na atividade leiteira", na qual a repórter usa expressões como: "dono do seu próprio negócio", "estabilidade financeira com apoio da Emater", "já construiu a sua casa própria”, e "o jovem rural pode dar certo". Esta última frase já propicia diversas reflexões posteriores, como: o que significa dar certo? Como um jovem rural pode dar errado? Seria mudar-se para o centro urbano o fracasso do jovem rural? Esta associação entre "dar certo" e sucesso financeiro nos remete à lógica hegemônica do capital, que se faz presente no meio rural com a imposição do agronegócio.

Nas reportagens sobre "Os segredos da cachaça artesanal mineira" e "Doce de leite Dom Coimbra de Coimbra", o sucesso comercial destes produtos é celebrado e seus respectivos produtores têm espaço para narrar suas trajetórias, o apoio da Emater e estimular outros produtores a seguir a trilha do empreendedorismo. Expressões como: "caminhar com as próprias pernas", "histórias de sucesso", "deslanchar", "realizar sonhos" são muito utilizadas em diversas reportagens. Estes exemplos de sucesso são resultados de sistemas de fatores, sendo ingenuidade serem atribuídos apenas às variantes técnicas e dificilmente podem ser reproduzidos em meio a diferentes constantes sociais. Como exemplo, ao longo da reportagem sobre a cachaça mineira, o produtor confirma um investimento de $\mathrm{R} \$ 1.600 .00,00$ para tornar sua cachaça competitiva no mercado, soma que poucos produtores rurais podem dispor para incrementar suas atividades.

A perspectiva do agronegócio propaga um meio rural homogêneo e seu "território" quase que exclusivo, sendo que muitos segmentos sociais existentes neste universo são marginalizados e "vistos pela ótica da disfuncionalidade social e como fator de atraso, salvo quando conseguem "superar" essa condição e se articular, de forma subordinada, à lógica do agronegócio" (OLIVEIRA, 2012), como indígenas, comunidades quilombolas, agricultores de subsistência, boias-frias ou posseiros. O discurso midiático tende a apresentar o meio rural pela ótica produtiva, destacando como 
modelo de sujeito rural aqueles que têm condições financeiras e espaciais de se inserir no processo de modernização, o que atende aos interesses do agronegócio.

\section{Considerações finais}

Enquanto um agente de extensão rural, o programa Minas Rural tem se consolidado como ferramenta de divulgação das ações da Emater-MG, focado na promoção de um meio rural estruturado principalmente em bases econômicas. Desta forma, deixa de trazer à luz um gradiente de tons do meio rural que deixam assim, de encontrar-se representados entre os casos de sucessos provindos de ações da Emater-MG. Embora alguns elementos de um meio rural menos homogêneo sejam apresentados no programa, não ocupam as mesmas proporções da vida real.

Ênfases no discurso e nas narrativas do programa contribuem para a construção de uma imagem que busca retratar o agronegócio como o principal resultado esperado para as assistências técnicas da Emater, restringindo a representação do universo da agricultura familiar. Para ampliar a representatividade do pluralismo rural dentro das ações comunicacionais da Emater, muitos passos devem ser seguidos, como redimensionar o espaço social rural, inserindo aqueles sujeitos que não se enquadram, ou não desejam se enquadrar, no cenário do agronegócio.

Algumas considerações podem ser adiantadas sobre o que a Emater apresenta como resultado de suas interferências no campo, através do programa Minas Rural, como a intensa valorização que o programa atribui ao sucesso comercial, não relacionando outros fatores como saúde ou bem-estar aos resultados dos trabalhos técnicos. Considerando-se os limites dos recursos naturais planetários, a desigualdade social centenária e os demais fatores que estratificam a sociedade, pode-se esperar que nem todos os produtores rurais alcancem este patamar de "sucesso" por inúmeras razões.

A sustentabilidade, quando elencado pelo programa, aparece mais aliada ao desenvolvimento, não sendo em si um objetivo a ser alcançado em favor da qualidade de vida ou do bem global.

Espera-se que o presente trabalho possa contribuir para uma reflexão sobre o modo homogêneo como a Emater MG vem divulgando suas práticas extensionistas e possa fornecer subsídios iniciais para que esta e outras instituições aperfeiçoem seu 
processo de comunicação rural, desenvolvendo projetos mais abrangentes e com possibilidades de novas perspectivas.

\section{Referências bibliográficas}

AQUINO, Joacir; SCHNEIDER, Sérgio. Pronaf e o desenvolvimento rural brasileiro: avanços, contradições e desafios para o futuro. In Políticas públicas de desenvolvimento rural no Brasil. Porto Alegre: Ed. da UFRGS, 53-81, 2015.

BORDENAVE, J.E.D. O que é Comunicação Rural?. São Paulo: Editora Brasiliense, 1983.

CANTÚ, Adriana; CIMADEVILlA, Gustavo. Comunicación y Ruralidad. Vigencia y obsolescencia de las teorías clásicas. Comunicación, Ruralidad y Desarrollo. Buenos Aires: Edições INTA, 2015.

CAPORAL, Francisco; RAMOS, Ladjane. Da extensão rural convencional à extensão rural para o desenvolvimento sustentável: enfrentar desafios para romper a inércia. Brasilia, 2006.

CAPORAL, Francisco. "Lei de ATER: Exclusão da Agroecologia e outras armadilhas". Caderno de Agroecologia, v.6, n.2, dez. 2011.

COELHO, F. M. G. A arte das orientações técnicas no campo. 1. ed. Viçosa: UFV, 2005.

ENTMAN, R. M. Framing: Toward Clarification of a Fractured Paradigm. Journal of Communication - Northwestern University, 1993.

FONSECA, Maria Teresa L. A Extensão Rural no Brasil, um projeto educativo para o capital. São Paulo: Edições Loyola, Coleção Educação Popular n 3, 1985.

FREIRE, Paulo. Extensão ou Comunicação. São Paulo: Ed Paz e Terra, 1977.

GUIMARÃES, Eduardo. Produção e Circulação do Conhecimento. Campinas: Pontes Editores,2001.

GRISA, C.; SCHINEIDER, S. Três gerações de políticas públicas para agricultura familiar e interação entre Estado e Sociedade Civil no Brasil. RESR, v. 52, n. Supl. 1, p. S125-S146, 2014.

HEREDIA, B., PALMEIRA, M., LEITE S. P., Sociedade e Economia do "Agronegócio" no Brasil., Revista Brasileira de Ciências Sociais, Vol. 25 n o. 74, 2010.

MARTIN-BARBERO, Jesus. Dos meios às mediações-comunicação, cultura e he gemonia. Rio de Janeiro: UFRJ, 2006.

MORRIS, Charles. Signos, Lenguage y Conducta. Buenos Aires: Losada, 2003.

OLIVEIRA, Valdir de Castro. Indústria cultural e meio rural. Revista Mediação, Belo Horizonte, v. 14, n. 14, jan./jun. de 2012.

ROSA, Caroline Petian. C\&T NO MEIO RURAL: A divulgação de Ciência e Tecnologia no programa televisivo Caminhos da Roça. Dissertação de Mestrado. Programa de Pós-Graduação em Comunicação Social da Universidade Metodista de São Paulo, Universidade Metodista de São Paulo - São Bernardo do Campo - SP, 2008.

SILVERSTONE, Roger. Por que estudar mídia. São Paulo: Editora Loyola,1999. 